\title{
Medicina tradicional indígena em tempos de pandemia da COVID-19
}

\author{
Traditional indigenous medicine in the pandemic times of COVID-19
}

\author{
Medicina indígena tradicional em los tiempos de la pandemia de COVID-19
}

José Erivaldo Gonçalves ${ }^{1 *}$, Ryanne Carolynne Marques Gomes Mendes², Wellington Manoel da Silva $^{3}$, Bianca Cardoso Peixinho ${ }^{1}$, Midian Beatriz de Oliveira ${ }^{2}$, Jessika Luana da Silva Albuquerque ${ }^{4}$, Jivaldo Gonçalves Ferreira ${ }^{3}$, Willaine Balbino de Santana Silva ${ }^{5}$, Leidyanne Soares Gomes ${ }^{6}$, Girdilliane Regina Silva de Araújo ${ }^{7}$.

\section{RESUMO}

Objetivo: Discutir sobre a medicina tradicional indígena em tempos de pandemia da COVID-19. Revisão bibliográfica: Apesar de difundida nos últimos anos, a implementação da medicina tradicional indígena no sistema oficial de saúde ainda é precária e carente de iniciativas mais eficientes. Em tempos de pandemia da COVID-19, os povos indígenas podem enfrentar algumas dificuldades nas suas práticas culturais, sobretudo na utilização da sua medicina tradicional, a qual deve ser respeitada conforme a Política Nacional de Atenção à Saúde dos Povos Indígenas. Considerações finais: A medicina tradicional indígena, objeto da política indigenista de saúde, está sendo utilizada como prática preventiva e de tratamento da COVID-19, na forma de práticas espirituais e uso de plantas medicinais por exemplo. Contudo, algumas dificuldades são evidenciadas como: manter o isolamento social, preocupações com os hábitos e cultura da população, associação entre a medicina tradicional com o modelo biomédico e o manejo dos cadáveres.

Palavras-chave: Medicina tradicional, Infecções por coronavírus, Saúde de populações indígenas.

\section{ABSTRACT}

Objective: To discuss traditional indigenous medicine in the pandemic times of COVID-19. Bibliographic review: Despite the diffusion in recent years, the implementation of traditional indigenous medicine in the official health system is still precarious and lacks more efficient initiatives. In the pandemic times of COVID19 , indigenous peoples may face some difficulties in cultural practices, especially in the use of their traditional medicine, and must be respected in accordance with the National Policy on Health Care for Indigenous Peoples. Final considerations: Traditional indigenous medicine, object of the indigenous health policy, is being used as a preventive and treatment practice for COVID-19, in the form of spiritual practices and medicinal plants, for example. However, some difficulties are evident, such as: maintaining social isolation, being concerned with the habits and culture of the population, associating with traditional medicine with the biomedical model and handling of corpses.

Keywords: Coronavirus infections, Health of indigenous populations, Traditional medicine.

\section{RESUMEN}

Objetivo: Discutir la medicina tradicional indígena en los tiempos de pandemia de COVID-19. Revisión bibliográfica: A pesar de la difusión en los últimos años, la implementación de la medicina tradicional indígena en el sistema oficial de salud aún es precaria y carece de iniciativas más eficientes. En los tiempos de la pandemia de COVID-19, los pueblos indígenas pueden enfrentar algunas dificultades en las prácticas culturales, especialmente en el uso de su medicina tradicional, y deben ser respetados de acuerdo con la Política Nacional de Atención de Salud para los Pueblos Indígenas. Consideraciones finales: La medicina indígena tradicional, objeto de la política de salud indígena, se está utilizando como práctica preventiva y de

\footnotetext{
${ }^{1}$ Centro de Pesquisas Aggeu Magalhães, Fundação Oswaldo Cruz (CpqAM/FIOCRUZ), Recife - PE.

*E-mail: goncalves.erij@gmail.com

2 Universidade Federal de Pernambuco (UFPE), Recife - PE.

${ }^{3}$ Instituto de Medicina Integral Professor Fernando Figueira (IMIP), Recife - PE.

${ }^{4}$ Centro Universitário da Vitória de Santo Antão (UNIVISA), Vitória de Santo Antão - PE.

${ }^{5}$ Faculdade de Ciências Médicas, Universidade de Pernambuco (FCM/UPE), Recife - PE.

${ }^{6}$ Secretaria Municipal de Jaboatão dos Guararapes, Jaboatão dos Guararapes - PE.

7 Universidade de Pernambuco (UPE), Recife - PE.
} 
tratamiento para COVID-19, en forma de prácticas espirituales y plantas medicinales, por ejemplo. Sin embargo, algunas dificultades son evidentes, tales como: mantener el aislamiento social, preocuparse por los hábitos y la cultura de la población, asociarse con la medicina tradicional con el modelo biomédico y manejar cadáveres.

Palabras clave: Infecciones por coronavirus, Medicina tradicional, Salud de las poblaciones indígenas.

\section{INTRODUÇÃO}

Desde a Conferência Nacional de Proteção à Saúde do índio, que ocorreu no mês de novembro de 1986, diversos aspectos relacionados as políticas de saúde voltadas para grupos indígenas foram discutidos e implementados. O que torna necessário a retomada destes temas e reflexões sobre as consequências da aplicação das novas recomendações do Sistema Único de Saúde (SUS) para as comunidades indígenas, visto suas especificidades e peculiaridades na conjuntura social brasileira (MAGGI RS, 2014).No Brasil, a assistência à saúde das populações indígenas, historicamente exploradas, possui uma trajetória marcada por ações e serviços, na maior parte das vezes, não equânimes e sem respeito a cultura desses povos. Apenas a partir dos séculos XVIII e XIX, devido a influência dos pensadores iluministas, é que os conceitos de igualdade, fraternidade, liberdade, ganharam evidência, por toda América, incluindo o Brasil. A partir desse momento, foram iniciados os processos a favor da independência, de modo que algumas políticas públicas que tinham como beneficiários os grupos sociais marginalizados começaram a ser instituídas.

O primeiro Serviço de Proteção aos Índios (SPI), surgiu no Brasil, apenas em 1910, ainda vinculado ao Ministério de Agricultura, desta forma, as questões envolvendo propriedade das terras eram priorizadas em detrimento à saúde (MAGGI RS, 2014). A década de 1950 foi marcada pela criação do Serviço de Unidades Sanitárias Aéreas (SUSA) vinculado ao Ministério da Saúde (MS), que se destinava a prestar assistência as regiões mais remotas e de difícil acesso.

No ano de 1997 ocorreu a criação da Fundação Nacional do Índio (FUNAI), mas que por diversos fatores de provocou insatisfações generalizadas, o que induziu os legisladores a desenvolver um modelo de atendimento que pudesse ser mais específico para atender as demandas das populações indígenas na constituição Federal de 1988. Juntamente com a criação do Sistema Único de Saúde (SUS), em 1991 a saúde indígena deixou de ser coordenada pela FUNAI e passou a ser coordenada pelo MS (MAGGI RS, 2014).

Diante desse cenário e de lutas e esforços de vários movimentos sociais, foi criada através da Lei AROUCA em 1999 a Política Nacional de Atenção à Saúde dos Povos Indígenas (PNASPI). Essa política visa a promoção do cuidado, do respeito e da articulação entre a cultura dos povos indígenas com o Sistema Único de Saúde (SUS) (PERES AO, et al., 2020). A PNASPI foi implementada em 2002 com o objetivo de cessar a negligência à saúde indígena, tema motivo de debates constantes, já que essas populações possuem um perfil epidemiológico distinto das demais sendo ainda vulneráveis às enfermidades trazidas pelo processo de colonização, além de habitarem em sua maioria das vezes regiões de difícil acesso.

Segundo dados do Instituto Brasileiro de Geografia e Estatística (IBGE) (2012), o Brasil possui uma população de 896.917 indivíduos indígenas, que correspondem a $0,4 \%$ da população total brasileira. Presentes em todos as unidades federativas brasileiras, os indígenas compõem uma população heterogênea distribuída em 305 etnias que falam 274 línguas diferentes. É sabido que a concepção do processo saúdedoença-cuidado pela população indígena é totalmente diferente do modelo biomédico apregoado pelo homem branco, o que leva a dificuldades na articulação dessas formas de cuidado. A ausência de formação e vivencia junto a realidade indígena causa incompreensão, discriminação, exclusão e preconceito limitando o acesso a saúde dessa população (PERES AO, et al., 2020; BRASIL, 2002).

Neste contexto, destaca-se que a PNASPI aborda a valorização da medicina tradicional indígena, de modo a articular os sistemas tradicionais de cura ao modelo biomédico a modo de potencializar a recuperação e diminuir os agravos à saúde, uma vez que cada sociedade tem seus próprios sistemas de prevenção, tratamento e de cura os quais devem ser respeitados (BRASIL, 2002).

A medicina tradicional indígena pode influir diretamente na relação com os serviços e ações de saúde, causando impasses quanto a procura ou não do sistema oficial de saúde ou ainda, a não aceitabilidade de 
intervenções e medidas de educação em saúde. Portanto, os processos de saúde-cuidado neste ou em outros contextos não ocorrem simplesmente através da transferência de conhecimentos ou pelo uso das tecnologias da biomedicina, mas por conceitos mais aprofundados e íntimos de contato com dimensões espirituais, ritualísticas, simbólicas e da natureza (BRASIL, 2002; SILVA HCC e DIAS MDGS, 2020).

Diante do surgimento da pandemia, causada pela disseminação do novo coronavírus (SARS-CoV-2), temse em particular maior preocupação com os povos indígenas, sobretudo pelo aumento de casos da doença nesta população. Assim, no Brasil, a expansão da COVID-19 para as áreas indígenas tornou-se uma emergência de saúde pública, pois esses povos, ao longo da história, têm sido impactados por epidemias de doenças infectocontagiosas, o que contribuiu para a dizimação e para a alta taxa de morbimortalidade dessa população (PONTES AL, et al., 2020).

Desde que a pandemia chegou ao Brasil, cerca de 2.085 indígenas aldeados foram contaminados pelo SARS-CoV-2 e 82 deles vieram a óbito em decorrência do agravamento da covid-19. Em cerca de 500 aldeias foram registrados casos de infecção pelo novo coronavírus, o que corresponde a $8,5 \%$ dos 5.852 agrupamentos existentes no País (VALENTE J, 2020).

Tais dados, demonstram a vulnerabilidade da população indígena à COVID-19, a qual é intensificada pela carência de infraestrutura de saneamento, domicílios com maior média de moradores, compartilhamento de utensílios, distância dos serviços de saúde de alta complexidade e ausência de meios de transportes, o que reforça a demanda de atenção urgente a essa população. Estando assim, essa vulnerabilização associada às condições econômicas e sociais em saúde (PONTES AL, et al., 2020).

No contexto da pandemia, a medicina tradicional é usada como mecanismos de cura e conforto para os povos indígenas, porém emergem preocupações acerca do contato que muitas vezes essas práticas requerem, principalmente dos líderes espirituais como o pajé com os índios suspeitos ou contaminados pelo SARS-CoV-2, já que é um vírus com alto poder de transmissão e infectibilidade. Para além disso, é notório e real que os serviços de saúde não dispõem de infraestrutura ou recursos adequados para os atendimentos dos indígenas, muito menos uma intertransculturalidade para compreender e respeitar processos diversos como o adoecer, o luto e a morte nesta população (CONSTANT JC, 2019).

Diante do exposto faz-se necessário refletir acerca da medicina tradicional indígena no contexto da COVID-19, pois é necessário que os direitos humanos dessa população sejam garantidos em relação às diferenças e particularidades culturais. Além disso, às práticas de cura tradicional que estão sendo utilizadas por comunidades indígenas no combate e enfrentamento à pandemia devem ser respeitados e acolhidos em suas particularidades, o que já e recomendado pela Organização Mundial de Saúde (OMS). Apesar da magnitude dessas questões, ainda são escassos os estudos que abordam essa temática. Sendo assim, a realização deste estudo, o qual tem por objetivo discutir sobre a medicina tradicional indígena em tempos de pandemia da COVID-19 de fundamental importância.

\section{REVISÃO BIBLIOGRÁFICA}

\section{Cataclismo biológico e COVID-19}

Para além da política, economia e cultura de maneira geral, cada sociedade constrói, por meio de mecanismos biológicos, ambientais e epigenéticos, combinações e recombinações de cargas de virais, bacterianas e parasitárias, que dão origem as doenças e infecções próprias daquela população. Em condições de isolamento, como no caso da população indígena, os indivíduos produzem uma combinação de agentes patogênicos muito peculiar, que parece atenuar-se mediante associações com o modo de vida dos sujeitos (RIBEIRO D, 2006).

Nessas condições, essas populações tornam-se extremamente sensíveis e vulneráveis quando expostas a agentes nocivos de outras culturas, o que é evidenciado pelas altas taxas de mortalidade as quais e evidenciado na comunidade receptora. A história revela, que antes da chegada dos Europeus e Africanos às Américas poucas eram as doenças que existiam entre os povos Ameríndios, estando estas doenças relacionadas principalmente aos ferimentos advindos da caça, problemas respiratórios e intoxicações alimentares, fazendo parte do influxo da natureza e do processo evolutivo do homem. Assim, essas moléstias 
eram tratadas a partir da medicina tradicional a qual usava ervas, rituais e elementos da natureza para alcançar a cura. Destarte, os indígenas viviam em harmonia com a natureza até essa condição ser rompida com o atraque das naus portuguesas em solo Americano (OLIVEIRA PH, 2009).

Inúmeras etnias foram extintas em consequência do que hoje, num eufemismo envergonhado, chama-se de "encontro" de sociedades do Antigo e do Novo Mundo. Este processo complexo envolveu dois agentes principais, o homem e os microrganismos. Visto que as barreiras epidemiológicas favoráveis às américas e desfavoráveis à África intensificou a introdução de dezenas de doenças e infecções aos povos indígenas, como por exemplo: varíola, sarampo, coqueluche, peste bubônica, catapora, difteria, tétano, tifo, gripe e possivelmente malária (BUCHILLET D e PIERRE G, 1998).

De acordo com o antropólogo Henry Dobyns as epidemias são tidas como um dos maiores cataclismos biológicos do mundo. Esses eventos representam um dos mecanismos mais antigos, mas ainda prevalente nos dias atuais de "despopulação indígena" (CUNHA MC, 2006).

O caso Yanomami, retratado por Ramos na década de 70, revela que durante o primeiro ano da construção da Perimetral Norte, cerca de $22 \%$ da população de quatro aldeias atingidas pelas obras e em contato direto com trabalhadores, garimpeiros e empresários vieram a óbito devido às doenças infectocontagiosas e que, dois anos depois, mais de $50 \%$ dos habitantes de outras quatro comunidades sucumbiram a uma epidemia de sarampo (RAMOS AR, 1993).

Atualmente, a pandemia de COVID-19 iniciada na China, no final de 2019, já infectou mais de 3 milhões de pessoas em todo o mundo. Essa evolução não difere das pandemias já vividas no sentido de atingir de forma extremamente agressiva a população indígena. No Brasil, estima-se que o vírus já tenha afetado 123 etnias com mais de 11.800 mil casos acumulados e 230 mortes, segundo a Secretaria Especial de Saúde Indígena, sendo a região Norte do país a mais afetada (SESAI, 2020). Agravantes como vulnerabilidade de acesso aos serviços de saúde, alto potencial de dispersão do vírus e número de pessoas idosas nessas comunidades, contribuem para taxas alarmantes de internamentos e complicações da COVID-19. Além disso, desmatamento das florestas, queimadas, garimpos ilegais, empresários e seus trabalhadores e até mesmo profissionais de saúde sem a devida proteção podem disseminar o vírus entre os povos resultando na contaminação do SARS-CoV-2, o que provocaria altos índices de mortalidade.

A Secretaria Especial de Saúde Indígena (SESAI), por meio dos órgãos competentes, tem a missão de executar a PNASPI e planejar estratégias de proteção articulado entre os Distritos Sanitários Especiais Indígenas (DSEI), na intenção de mitigar os impactos causados por essas situações. Entre essas ações estão o envio de insumos e Equipamentos de Proteção Individual e a criação do Comitê de Crise Nacional para planejamento, execução e monitoramento dos impactos da COVID-19 nos povos indígenas. Para além das questões tecno-burocráticas, é necessário também reforçar os aspectos da política indigenista de saúde que considera a autonomia dos índios sobre os processos de cura e tratamento embasado nas crenças da etnia, bem como respeitar a medicina tradicional indígena como estrutura simbólica, espiritual, cultural e metafísica e de tratamento essencial em momentos de sofrimento. Assim, essas práticas precisam ser respeitadas de modo a tornar-se um processo sinérgico na recuperação e proteção desses sujeitos (BRASIL, 2002).

\section{Medicina tradicional indígena como objeto de políticas públicas}

Apesar de difundida nos últimos anos, a implementação da medicina tradicional indígena no Sistema Único de Saúde (SUS) de saúde ainda é precária e carente de iniciativas mais eficientes. Assim, reconhece-se a necessidade emergente do fortalecimento das práticas dessa sabedoria por meio de políticas públicas e de ações de revitalização cultural e simbólicas que são realizadas pelos povos indígenas com o objetivo de resguardar e resgatar a suas subjetividades. Apesar da importância dos estudos e pesquisas desenvolvidas com essa temática, estas ainda são incipientes, o que contribui de maneira gigantesca para manutenção de lacunas na produção de políticas e ações que visem assegurar o acesso a esse cuidado nas redes do SUS, inclusive nos próprios DSEl. Documentos como a declaração de Alma-Ata, em 1978, ou ainda as recomendações da OMS, na década de 1970, orientam os países e suas esferas a incorporarem estratégias que considerem a medicina tradicional como cuidado primário à saúde e de baixo custo. Em uma sociedade ocidental, aos moldes dos processos de colonização eurocêntrica, a hegemonia alopática nos processos de 
cura, tratamento e a prevenção tornam-se soberanos. Conforme, Coimbra CEA e Santos RV (2000) as particularidades do modo de existir da população indígena, numa sociedade cuja moral tende a eliminar o diferente em razão de uma coletividade excludente, reflete em condições de vida e saúde desiguais.

Esse talvez seja um dos maiores desafios aos sistemas nacionais de saúde na implementação desta racionalidade, visto que a medicina tradicional não comporta em si um rigor puramente cientifico e se constrói sem um padrão, pois os saberes são herdados das vivências e das interações comunais e espirituais do mundo particular de cada povo (OMS, 2013).

No Brasil, as recomendações internacionais são institucionalizadas por meio das políticas públicas. Marcos como a Política Nacional Atenção à Saúde População Indígena, e a Política Nacional de Plantas Medicinais e Fitoterápicos, aprovada por meio do Decreto № 5.813, de 22 de junho de 2006, reconhece a eficácia simbólica e empírica das medicinas tradicionais Indígenas e os direitos dos povos a sua cultura (BRASIL, 2002; BRASIL, 2006). Essas políticas são de caráter fundamental na construção de vínculos, experiências, fortalecimento e respeito as subjetividades e o entendimento do processo saúde-doença-cuidado, pois a procura pelos serviços de saúde estruturais nem sempre vai acontecer.

Os indígenas tratam as suas enfermidades primariamente através de redes familiares e comunitárias por onde os saberes e as práticas de cuidados tradicionais com a saúde estão amplamente difundidos (FERREIRA LO, 2013). E é neste cenário que os primeiros cuidados são estabelecidos para a recuperação do doente que também são tomadas as decisões quanto à busca de tratamento especializado, ou não, nisso, fortalecer o vínculo do cuidado e da ancestralidade é também desmitificar e ampliar o acesso à saúde dessa população.

\section{O impacto da COVID-19 na medicina tradicional indígena}

Desde 1992, a Organização das Nações Unidas (ONU), reconheceu o direito indígena acerca dos conhecimentos tradicionais. Dentre esses conhecimentos, destaca-se a medicina tradicional indígena, a qual é caracterizada pelo uso de plantas, ervas, animais, rituais, músicas, espiritualidade e crenças, com a finalidade de diagnosticar, prevenir, curar ou tratar enfermidades e sintomas de doenças físicas ou mentais. Além disso, se constitui como uma expressão do saber, prática e tradição dos povos indígenas, que é transmitida de geração em geração (MATOS MBM e NUNES MS, 2016; GUZMÁN-ROSASSC e KLEICHEDRAY M, 2017; ASSIS JT et al., 2018).

A utilização da medicina tradicional indígena se manifesta enquanto expressão cultural própria da população, a qual é praticada e amparada por crenças e também pela falta de acesso aos serviços de saúde. Ademais, pode-se haver resistência cultural por diferi das práticas biomédicas (ASSIS JT, et al., 2018). Contudo, em tempos de pandemia da COVID-19, os povos indígenas podem enfrentar algumas dificuldades nas suas práticas culturais, sobretudo na utilização da medicina tradicional. Dentre as dificuldades tem-se: 0 desafio de manter o isolamento social devido ao modo de vida e cultura da população, visto que os indivíduos doentes ou suspeitos pela contaminação do novo coronavírus vão em busca do pajé para ter os cuidados à saúde (OPAS, 2020).

Além disso, em algumas etnias, o hábito de cumprimentar o outro com aperto de mão e contato corporal é comum e, caso essa prática seja negada, considera-se uma forma de desrespeito, o que torna complexa a doção de medidas de prevenção direcionadas a minimizar impactos da disseminação do vírus, já que tanto os aspectos culturais quanto os aspectos preventivos devem ser levados em consideração nas orientações de controle (LIZARDO L, 2020).

Assim, as equipes de saúde devem se articular com os povos indígenas, ofertando orientações para esse grupo étnico proteger sua saúde. As orientações podem ser: evitar aglomerações e contato físico; preparar moradores caso alguém da família adoeça; associar o uso da medicina tradicional com o tratamento médico; garantir cuidados e proteção aos vulneráveis. Para tanto, é necessário que, ao considerar a medicina tradicional como importante ferramenta do cuidado à saúde indígena, bem como as práticas e costumes, o curandeiro trabalhe com os profissionais de saúde para verificar se o uso de determinadas plantas medicinais é aconselhável para lavagem das mãos, prevenção e tratamento da doença (OPAS, 2020). 
Outros aspectos a serem considerados são os costumes e tradições dos povos indígenas para o manejo de cadáveres no contexto da pandemia. É necessário, respeitar à cosmovisão e à diversidade cultural dessa população. Assim, é importante assegurar uma abordagem intercultural no controle da COVID-19, de forma que ocorra a avaliação das práticas de saúde, que podem ou não entrar em conflito com o modelo biomédico. Considera-se também que as práticas culturais e espirituais da população indígena devem ser estudadas com a finalidade de implementar abordagens de estratégias de diagnóstico, tratamento e de medidas de isolamento social (OPAS, 2020).

Dessa forma, sabe-se que os povos indígenas têm sua própria cosmovisão e saberes ancestrais, bem como conhecem uma variedade de plantas medicinais para prevenir e curar enfermidades, que são usadas em resposta aos problemas de saúde que se manifestam nas aldeias e consequentemente são usados contra a COVID-19 com a finalidade de conter a disseminação da doença. Assim, utilizam as plantas medicinais que servem para doenças e infecções respiratórias mais simples e são estimulados a combater o vírus. Contudo, ainda não se sabe se alguma planta é eficaz para a nova doença do século $\mathrm{XXI}$, mas as práticas dessa população devem ser respeitadas conforme as diretrizes da PNASPI (ACOSTA ML, 2020).

\section{CONSIDERAÇÕES FINAIS}

A medicina tradicional indígena, objeto da política indigenista de saúde, está e deve ser utilizada como prática preventiva e de tratamento da COVID-19. Contudo, algumas dificuldades como: manter o isolamento social, preocupações com os hábitos e cultura da população, associação entre a medicina tradicional com o modelo biomédico e o manejo dos cadáveres nessa cultura. Deve-se considerar as particularidades dessa população de modo a reduzir os índices de morbimortalidade e não reproduzir processos coloniais de vulnerabilização e exterminação desses povos. Ademais, ressalta-se a importância de estudos com esta população no contexto da pandemia, visto que estes ainda são escassos.

\section{REFERÊNCIAS}

1. ACOSTA ML. Pueblos indígenas y afrodescendentes y las medidas para enfrentar el COVID-19. Nicarágua: Academia de Ciências de Nicarágua; 2020. p. 36.

2. ASSIS JT, et al. Medicina tradicional no Brasil e em Moçambique. O Público e o Privado, 2018;16(1): 13-30.

3. BRASIL. A Política de Atenção à Saúde Indígena no Brasil. 2ed. Brasília: Ministério da Saúde, 2002; 42p.

4. BRASIL.A Política Nacional de Plantas Medicinais e Fitoterápicos. 1ed. Brasília: Ministério da Saúde, 2006; 60p.

5. BRASIL. Boletim Epidemiológico da SESAI - Covid-19. Brasília: Ministério da Saúde, 2020.

6. BRASIL. Decreto 9795/19 | Decreto no 9.795, de 17 de maio de 2019. Aprova a Estrutura Regimental e o Quadro Demonstrativo dos Cargos em Comissão e das Funções de Confiança do Ministério da Saúde, remaneja cargos em comissão e funções de confiança, transforma funções de confiança e substitui cargos em comissão do Grupo-Direção e Assessoramento Superiores - DAS por Funções Comissionadas do Poder Executivo - FCPE. Diário oficial da União. 3 de julho de 2020.

7. BUCHILLET D, GAZIN P. A situação da tuberculose na população indígena do alto rio Negro (Estado do Amazonas, Brasil). Caderno de Saúde Pública, 1998; 14(1): 181-185.

8. COIMBRA CEA, SANTOS RV. Saúde, minorias e desigualdades: algumas idéias de inter-relações com ênfase nos povos indígenas. Ciência e Saúde Coletiva, Rio de Janeiro, 2000; 5(1): 125-132.

9. CONSTANT JC. A Terra é de vocês! Compreendendo a efetivação do direito ao Território no seio do povo indígena Puyanawa. Revista Brasileira de Linguística Antropológica, 2019; 11(2): 1-10.

10. CUNHA MC. A história dos Índios do Brasil. 2. Ed. São Paulo: Companhia das letras, 2006.

11. FERREIRA LO. A emergência da medicina tradicional indígena no campo das políticas públicas. História, Ciência, Saúde-Manguinhos, 2013; 20(1): 203-219.

12. GUZMÁN-ROSAS SC, KLEICHE-DRAY M. La inclusión del conocimiento tradicional indígena enlas políticas públicas del Estado mexicano. Gestión y política pública, 26(2): 297-339.

13. INSTITUTO BRASILEIRO DE GEOGRAFIA E ESTATÍSTICA (IBGE). Censo 2010: características gerais dos indígenas - resultados do universo. Rio de Janeiro: IBGE, 2012.

14. LIZARDO L. 2020. O impacto do Covid-19 entre o povo Hupd'äh [Reflexões ameríndeas em tempos de pandemia]. Disponível em: https://ds.saudeindigena.icict.fiocruz.br/handle/bvs/1816. Acesso em: 3 jul. 2020.

15. MAGGI RS. A saúde indígena no Brasil. Revista Brasileira de Saúde Materno-Infantil, 2014, 14(1): 13-14.

16. MATOS MBM, NUNES MS. Medicina tradicional: terapia indígena no estado do Acre. Journal of Amazon Health Science, 2016; 2(1): 1-32.

17. OLIVEIRA PH. Direito indígena à saúde: proteção constitucional e internacional. Dissertação (Mestrado em Direito) Pontifícia Universidade Católica de São Paulo, São Paulo, 2009; 335p. 
18. ORGANIZAÇÃO PAN-AMERICANA DE SAÚDE (OPAS). 2020. Considerações sobre povos indígenas, afrodescendentes e outros grupos étnicos durante a pandemia de COVID-19. Disponível em: https://iris.paho.org/handle/10665.2/52280. Acesso em: 3 jul. 2020.

19. ORGANIZACION MUNDIAL DE LA SALUD (OMS). 2013. Estratégia da OMS sobre medicina tradicional: $2014-2023$. Disponível em: https://www.who.int/medicines/publications/traditional/trm_strategy14_23/en/.Acesso em: 3 jul. 2020.

20. PERES AO, et al. Saúde indígena e dificuldades no acesso ao sistema público de saúde no Amazonas. Boletim Informativo Unimotri saúde em Socio gerontologia, $2020 ; 19(13): 1-11$.

21. PONTES AL, et al. 2020. Vulnerabilidades, impactos e o enfrentamento ao Covid-19 no contexto dos povos indígenas: reflexões para a ação. Disponível em: https://www.arca.fiocruz.br/handle/icict/41196. Acesso em: 3 jul. 2020.

22. RAMOS AR. O papel político das epidemias: o caso Yanomami, Brasília,1993.

23. RIBEIRO D. A formação e o sentindo do Brasil. São Paulo: Companhia das letras, 2006.

24. RIBEIRO D. Os índios e a civilização. A integração das populações indígenas no Brasil moderno. São Paulo: Companhia das letras, 1996.

25. SILVA HHC, DIAS MDGS. Narrativas sobre a pandemia por COVID-19 nos estados do Amazonas e Roraima. Somanlu: Revista de Estudos Amazônicos, 2020; 1(1): 33-49.

26. VALENTE J. Covid-19: mais de 2 mil indígenas foram contaminados e 82 morreram. Agência Brasil. Disponível em: https://agenciabrasil.ebc.com.br/saude/noticia/2020-06/ministerio-da-saude-fala-sobre-combate-covid-19-na-saudeindigena. Acesso em: 16 jul. 2020. 